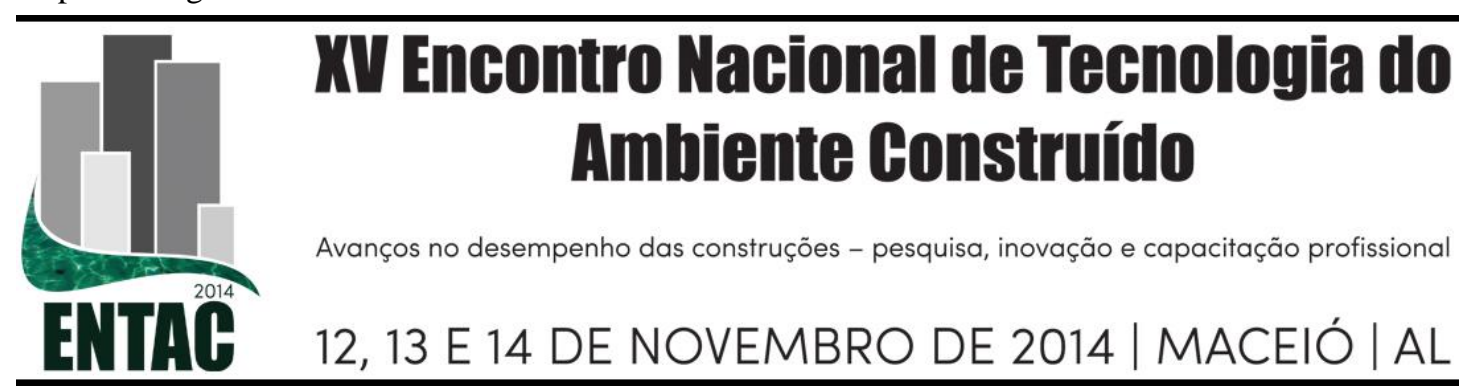

\title{
PANORAMA DAS MANIFESTAÇÕES PATOLÓGICAS EM MARQUISES NO CENTRO HISTÓRICO DE VITÓRIA/ES
}

\author{
VIEIRA, Geilma Lima (1); PANETO, Greicikelly Gaburro (2); JORDONI, Lorena \\ Simões (3), DORNELLAS, Angélica (4)
}

(1) UFES, e-mail: geilma.vieira@gmail.com (2) UFES, e-mail: arquitetando.x@gmail.com (3) UFES, e-mail: lorenacivil@yahoo.com.br (4) UFES, e-mail: angelicadornellas@hotmail.com

\begin{abstract}
RESUMO
Ao longo do tempo a função das marquises foi sendo modificada. Esses elementos construtivos, por estarem diretamente projetados sobre as vias públicas, podem representar sério risco à integridade do transeunte caso não tenham uma manutenção adequada. Diante disso a presente pesquisa visou realizar os estudos inicias para elaborar um panorama das principais manifestações patológicas das marquises, tomando como estudo de caso o centro histórico de Vitória, no Estado do Espírito Santo, área repleta de edificações datadas desde o séc. XVI e que possui uma situação ambiental propícia à deterioração estrutural devido a agentes externos e internos. Este trabalho teve como objetivo realizar um levantamento das manifestações patológicas encontradas em marquises no Centro Histórico de Vitória-ES. Para tanto foi realizada uma inspeção visual preliminar relacionando o tipo de manifestação patológica e sua frequência dentro do espaço analisado. Foram eleitas três áreas do centro histórico que pudessem representar o contex to regional, o que culminou em uma amostra de duzentas e vinte e cinco marquises. Os resultados apontam que mais da metade da amostra analisada possui alguma manifestação patológica, sendo que as maiores ocorrências foram de crescimento de micro-organismos e até mesmo vegetação, eflorescências, além de fissuras visíveis, culminando com corrosão das armaduras. Tais resultados foram considerados coerentes com o clima local, que possui elevada umidade relativa do ar, grande concentração de íons cloreto devido à proximidade com a baía de Vitória e elevado fluxo de veículos. Os resultados obtidos permitem concluir que as marquises analisadas necessitam de atenção voltada à sua recuperação e manutenção, e que de modo geral as mesmas representam risco à população. Além disso, é necessária maior conscientização da população, especialmente dos proprietários dos imóveis, aos problemas decorrentes das patologias a fim de evitar incidentes que gerem danos maiores, para que as marquises possam exercer uma função eficiente no ambiente urbano.
\end{abstract}

Palavras-chave: manifestações patológicas, durabilidade, manutenção.

\begin{abstract}
Over time the function of the marquees has been modified. These building elements, because they are directly projected onto public roads, can pose serious risk to the integrity of the passerby if they have not proper maintenance. Therefore this study aimed to perform the initial investigation to provide an overview of the major pathological manifestations of marquees, taking as case study the historical center of Vitoria, Espirito Santo, full of buildings dating from the Century XVI and where there is47 a favorable environmental situation of structural deterioration due to external and internal agents. This study aimed to survey the pathological changes found in the historic center of Vitoria - ES. A preliminary visual inspection relating the type of pathological manifestation and its frequency was performed within the space analyzed. Three areas of the historic center that could represent the regional context, which culminated in a sample of two hundred twenty-five marquees were elected. The results indicate that more than half of the sample analyzed has some pathological manifestation, being the largest occurrences were the growth of micro- organisms and even vegetation, efflorescence, and visible cracks, culminating with reinforcement corrosion. These results were considered consistent with the local climate, which has a high relative
\end{abstract}


humidity, high concentration of chloride ions due to the proximity to the bay and high flow of vehicles. The results indicate that the analyzed marquees require attention focused on the restoration and maintenance, and generally represent the same risk to the population. In addition, increased awareness of the population, especially the owners of the properties, problems resulting from pathologies to avoid incidents and the marquees can exercise an effective role in the urban environment.

Keywords: pathological manifestations, durability, maintenance.

\section{INTRODUÇÃO}

Segundo afirma Rizzo (s.d.), "a partir de 1902, com surgimento do Cimento Portland e a teoria de dimensionamento do concreto armado de Mörsch, houve um grande salto na tecnologia das estruturas", a construção de grandes edifícios tornou-se possível, e as cidades que contavam com construções de no máximo quatro pavimentos, iniciaram um processo de verticalização, inspiradas no modelo urbano americano. A partir disso, surgiu no Brasil a preocupação com o risco que a queda de objetos de grande altura traria para os pedestres. Foi criado então no Rio de Janeiro o Decreto $n^{\circ} 6000 / 1937$, que impôs condições para construção de marquises e tornou obrigatória a sua construção em prédios comerciais, e em outras edificações, dependendo do zoneamento. Em 1988, com o Decreto $n^{\circ} 8272 / 88$ e em 1991 com o Decreto $n^{\circ} 10426 / 91$ extinguia-se a obrigatoriedade de construção de marquises.

Cabe observar que o estado de conservação das marquises se dá devido a alguns fatores, tais quais sugere Carmo (2009), como falhas humanas durante o projeto, durante a construção e durante a utilização, além de causas naturais (físicas, químicas e biológicas). Ou seja, o método construtivo, o cobrimento, os materiais empregados, a forma de utilização além da durabilidade das estruturas de concreto são exemplos de fatores influenciadores de patologias. Consta na NBR 6118/2014 que a durabilidade "consiste na capacidade da estrutura resistir às influências ambientais previstas e definidas em conjunto pelo autor do projeto estrutural e o contratante, no início do trabalho de elaboração do projeto" (p.13).

Segundo Verçoza (1991 citado por Segat, 2005) os defeitos das edificações podem ser comparados a doenças, as quais apresentam manifestações patológicas. Essa analogia é muito utilizada na construção civil quando deseja-se analisar eventuais problemas nas edificações e dessa forma pode-se entender melhor a convenção do termo patologia das edificações.

\section{1 Área de estudo}

No Estado do Espírito Santo, a ilha de Vitória contém o primeiro perímetro urbano ocupado na região, onde foi fundada sua capital (Figura 1). O surgimento do chamado centro de Vitória deu-se primeiro na região que hoje é conhecida como Cidade Alta, local em que foi instalado o centro administrativo do Estado. Na década de 1920 houve um crescimento populacional, surgindo então a necessidade de expansão para as áreas vizinhas (VITÓRIA, s.d).

\section{Figura 1 - Localização da capital na ilha de Vitória.}




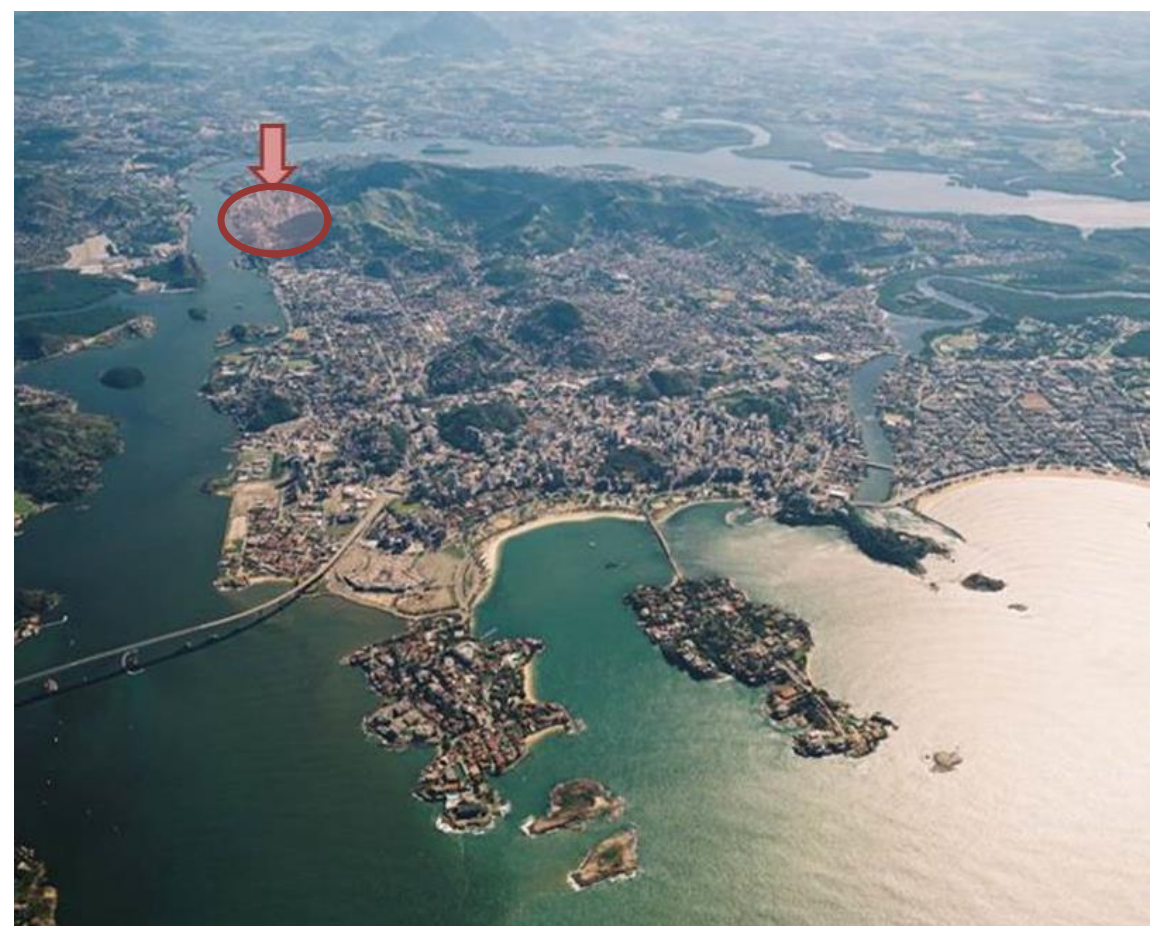

Fonte: Adaptada de Albuquerque (2009)

A partir da década de 1940 o processo de verticalização do centro foi se tornando mais intenso, sendo a construção de marquises bastante comum, especialmente na região do comércio (VITÓRIA, s.d).

Com o passar do tempo as construções tornaram-se antigas e a necessidade de manutenções periódicas tornou-se necessária, porém isso não ocorreu com a maior parte das edificações dessa região. Ao caminhar pelas ruas é perceptível o descaso com as marquises e o perigo que muitos transeuntes correm ao passar por debaixo de tais estruturas, como se observa na Figura 2. Alguns acidentes, que causaram ferimento em pessoas que passavam, foram registrados nos jornais locais.

Dessa forma há uma necessidade de verificação da situação das marquises do Centro de Vitória, diagnosticando os casos de forma que os proprietários dos imóveis possam corrigir as patologias que se apresentam, evitando assim desastres como os já ocorridos nessa região.

Figura 2 - Exemplo de estrutura diagnosticada na área de estudo. 


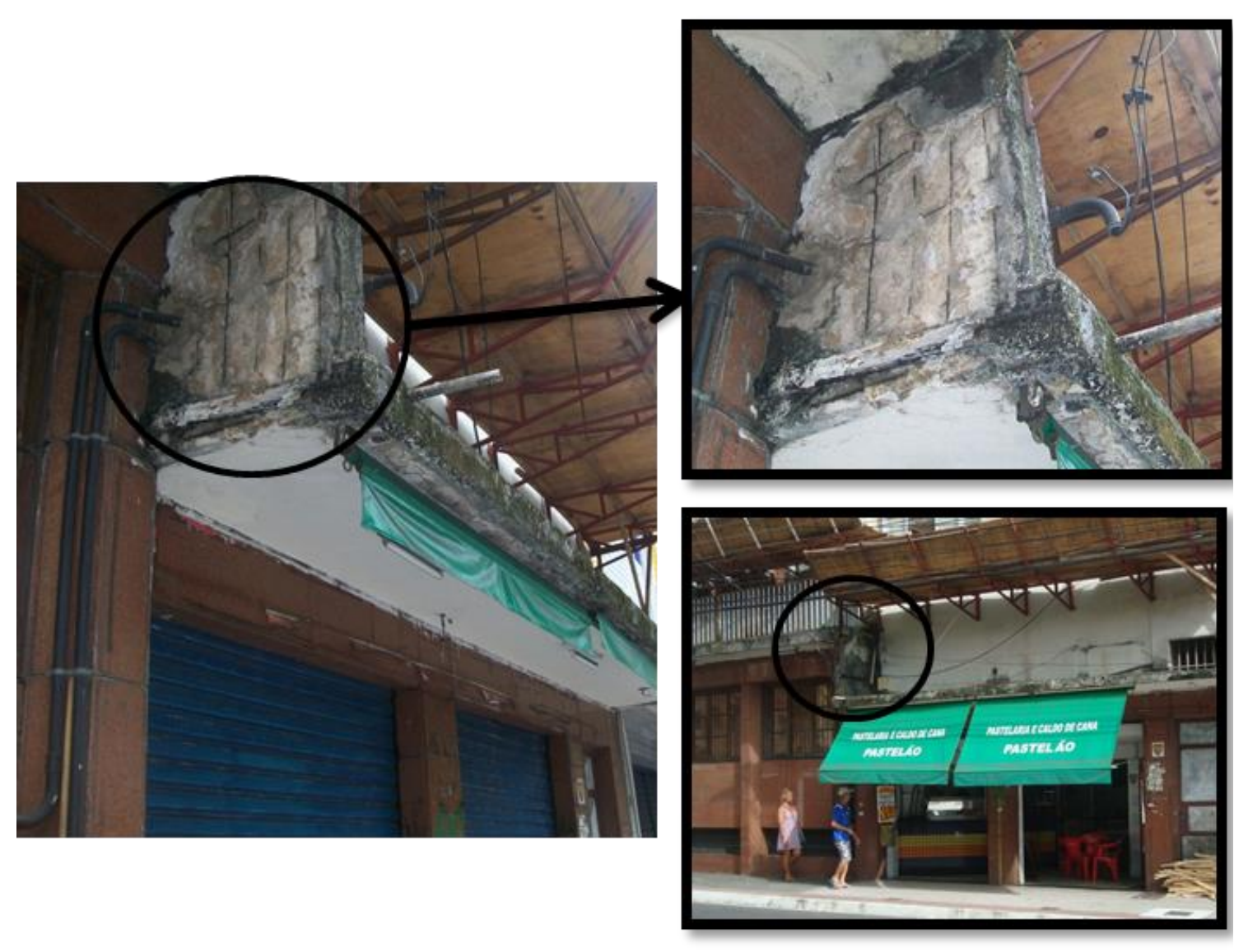

Fonte: Autores (2013)

\section{METODOLOGIA}

O objetivo dessa pesquisa foi avaliar o estado geral das marquises da região do centro de Vitória, relacionando o tipo de manifestação patológica e sua frequência dentro da amostra pesquisada.

Infundido na metodologia proposta por Castro (1994), que quantifica os tipos de dano em estruturas de concreto e os relaciona com as manifestações patológicas, classificando-os em função de sua importância e intensidade para cada elemento estrutural do estudo de caso, o presente estudo se restringe a uma inspeção preliminar visual dos elementos de marquises, o que significa que as manifestações não foram classificadas, bem como não foram realizados ensaios complementares, não foi feita análise de projeto e nem medições das estruturas in loco. De acordo com Filho (2003) citado por Carmo (2009) a presente análise classifica-se no nível 1 de rigor de inspeção conforme mostra o Quadro 1.

\section{Quadro 1 - Tipos de análises de manifestações patológicas.}

\begin{tabular}{|c|c|}
\hline Nível & Características \\
\hline 1 & $\begin{array}{c}\text { Inspeção para a identificação das patologias aparentes, elaboradas por } \\
\text { profissional habilitado; contratado com orientação técnica pertinente. }\end{array}$ \\
\hline 2 & $\begin{array}{c}\text { Inspeção para a identificação de patologias aparentes identificadas com o } \\
\text { auxílio de equipamentos, elaborada por profissionais habilitados. }\end{array}$ \\
\hline
\end{tabular}


3 Inspeção para a identificação de patologias aparentes, e das ocultas constatáveis com o auxílio de equipamentos, incluindo testes e ensaios locais e/ou laboratoriais específicos, elaborada por profissionais habilitados.

Fonte: FILHO (2003) citado por Carmo (2009)

A região do Centro de Vitória foi escolhida para a pesquisa por se tratar de uma área com alta concentração de marquises. A coleta de dados foi feita subdividindo o Centro de Vitória em três sub-regiões conforme mostra a Figura 3.

\section{Figura 3 - Sub-regiões analisadas.}

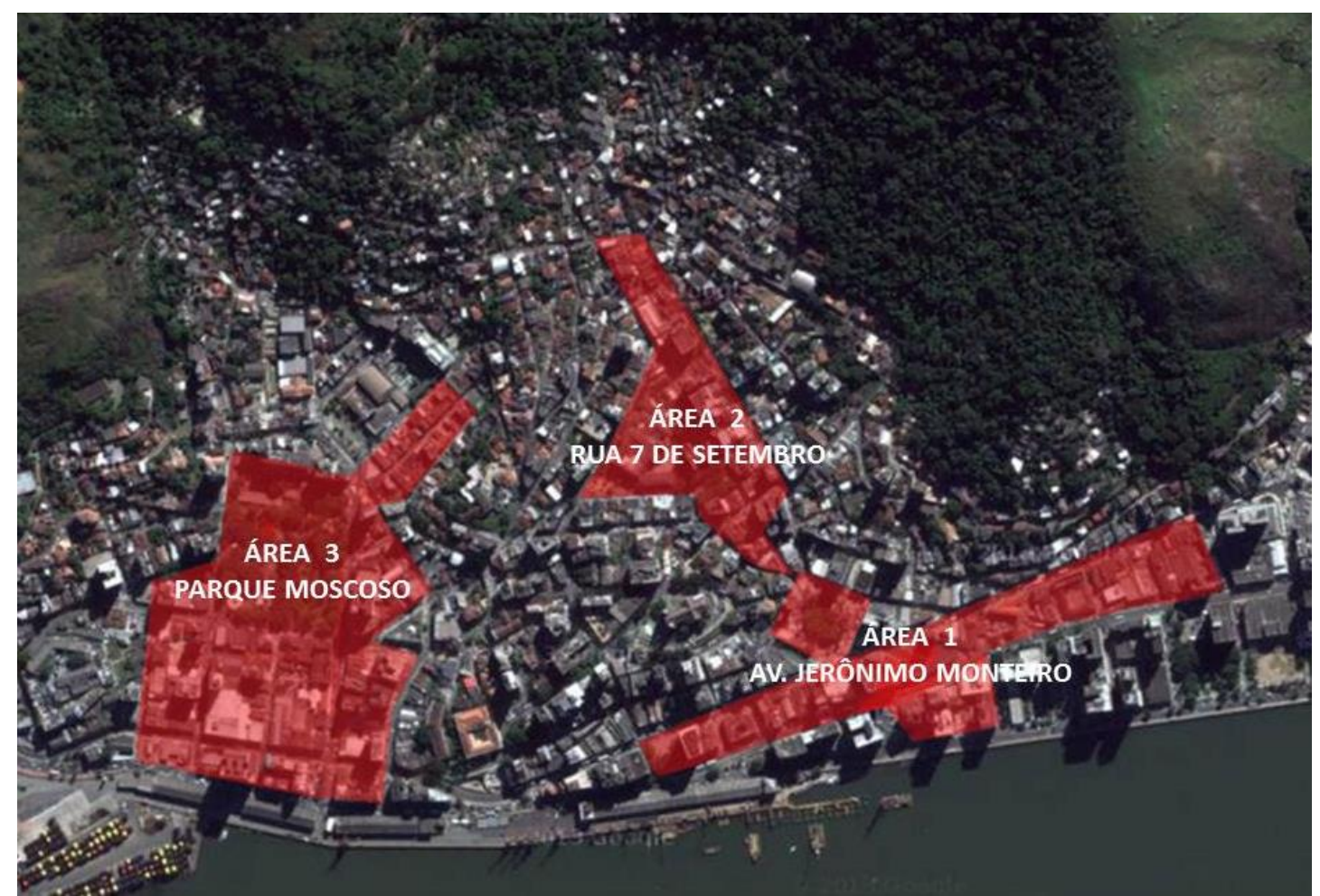

Fonte: Autores (2013)

As três áreas por sua vez constituem-se em:

- Área 1: Avenida Jerônimo Monteiro e proximidades;

- Área 2: Rua Sete de Setembro e proximidades;

- Área 3: Parque Moscoso e proximidades.

Essas sub-regiões foram escolhidas por se tratarem de locais onde o fluxo de veículos e transeuntes era mais elevado, sofrendo assim ação continua do dióxido de carbono $\left(\mathrm{CO}_{2}\right)$, além de ação abrasiva, concentração de íons cloreto e alta umidade relativa do ar por estar próxima a baía de Vitória.

Segundo a norma NBR 6118 (ABNT, 2014), a qual avalia a agressividade do meio em que o concreto está inserido, a área se encontra em um macro clima marinho e sua classe de agressividade ambiental pode ser considerada nível III - forte.

\section{RESULTADOS}

Foram avaliadas 225 amostras de marquises nas três áreas definidas e observou-se que 116 marquises apresentaram alguma manifestação patológica em sua estrutura conforme pode ser verificado na Tabela 1. 
Tabela 1 - Quantificação da amostra analisada e dos casos de manifestação patológica.

\begin{tabular}{|c|c|c|c|}
\hline $\begin{array}{c}\text { Área } \\
\text { analisada }\end{array}$ & Quantidade de marquises & $\begin{array}{c}\mathbf{N}^{\mathbf{0}} \text { de casos com } \\
\text { manifestação } \\
\text { patológica }\end{array}$ & $\%$ \\
\hline Área 1 & 92 & 49 & 53,26 \\
\hline Área 2 & 48 & 44 & 91,67 \\
\hline Área 3 & 85 & 23 & 27,06 \\
\hline Total & 225 & 116 & 51,56 \\
\hline
\end{tabular}

Fonte: Autores (2013)

A partir da Tabela 1 é possível constatar que a região em que a incidência de manifestações patológicas foi mais intensa foi a área 2. Esse fato pode ter sido causado por se tratar de uma área em que as ruas são mais estreitas e a ventilação muito prejudicada tornando o ambiente mais úmido e propício ao ataque de agentes externos. As variáveis analisadas são apresentadas no Quadro 2. Ressalta-se que nesse estudo avaliou-se apenas a ocorrência da manifestação, sem considerar sua intensidade.

Quadro 2 - Dados utilizados no check-list da avaliação preliminar.

\begin{tabular}{|l|l|}
\hline Elemento & \multicolumn{1}{|c|}{ Manifestação patológica } \\
\hline Revestimento & Descascamento \\
& Eflorescência \\
& Vesículas \\
& Desplacamento cerâmico \\
& Fissuras visíveis \\
& Microorganismos \\
& Manchamento de Calcinação \\
& Manchamento de Ferrugem \\
\hline Concreto & Deteriorado \\
\hline Ferragem & Exposta \\
& Apresenta corrosão \\
& Alteração diâmetro \\
\hline Outros & Alteração estrutural \\
& Sobrecarga \\
& Ocultação de marquise \\
\hline
\end{tabular}

Fonte: Autores (2013)

Uma característica marcante da área 01 por ser uma área bastante comercial foi a ocultação das marquises. Nas áreas 01 e 02 a manifestação mais frequente foi a incidência de microorganismos, já na área 03 foi de eflorescência. Os dados se encontram descritos na Figura 4.

Figura 4 - Frequências das manifestações patológicas por sub-área de estudo. 


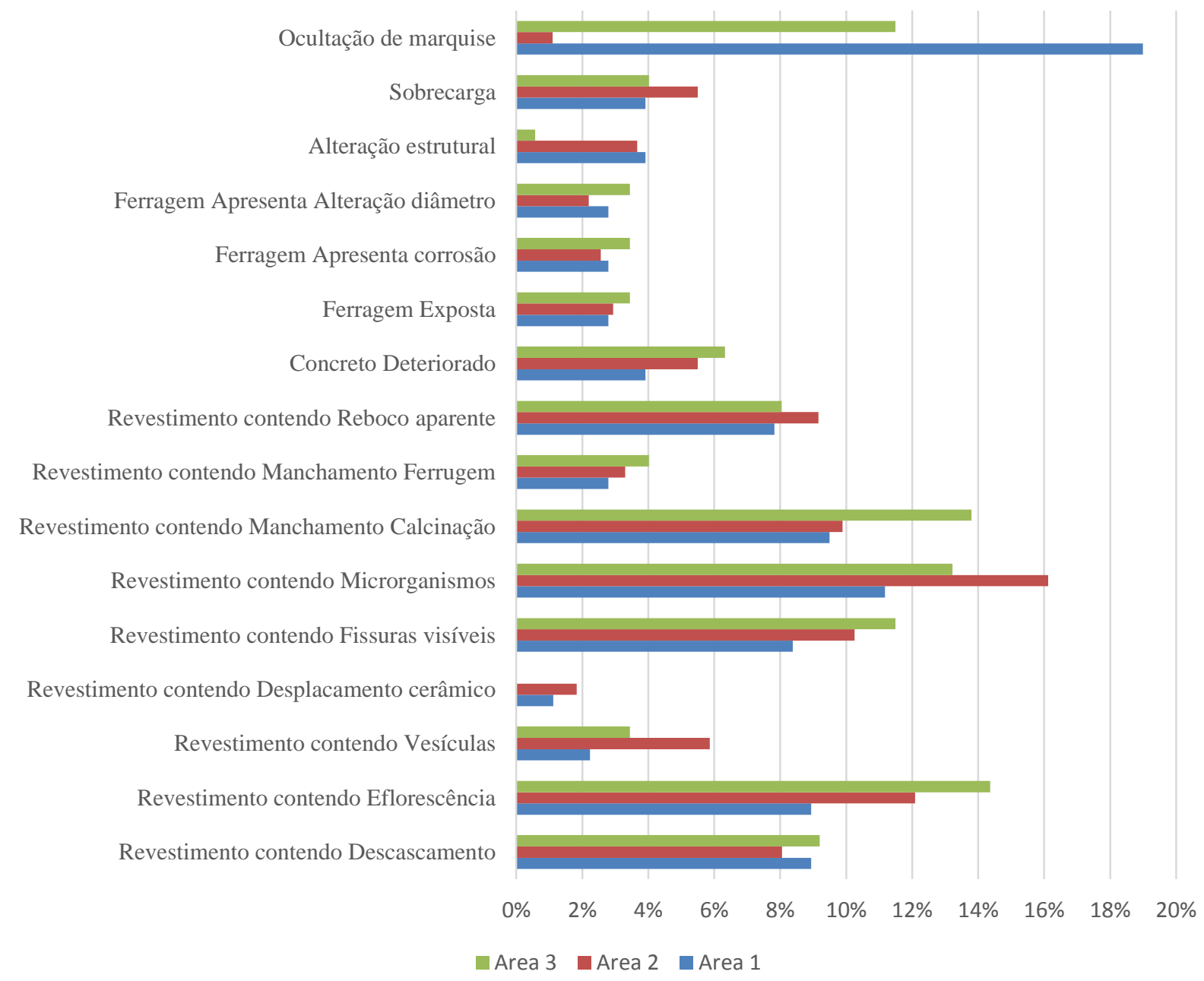

Fonte: Autores (2014)

Por fim, somando a quantidade total de cada variável por área, foi possível constatar a ocorrência global da amostra adotada e sua porcentagem, culminando nos resultados globais da Figura 5.

Figura 5 - Frequências gerais das manifestações patológicas das marquises. 


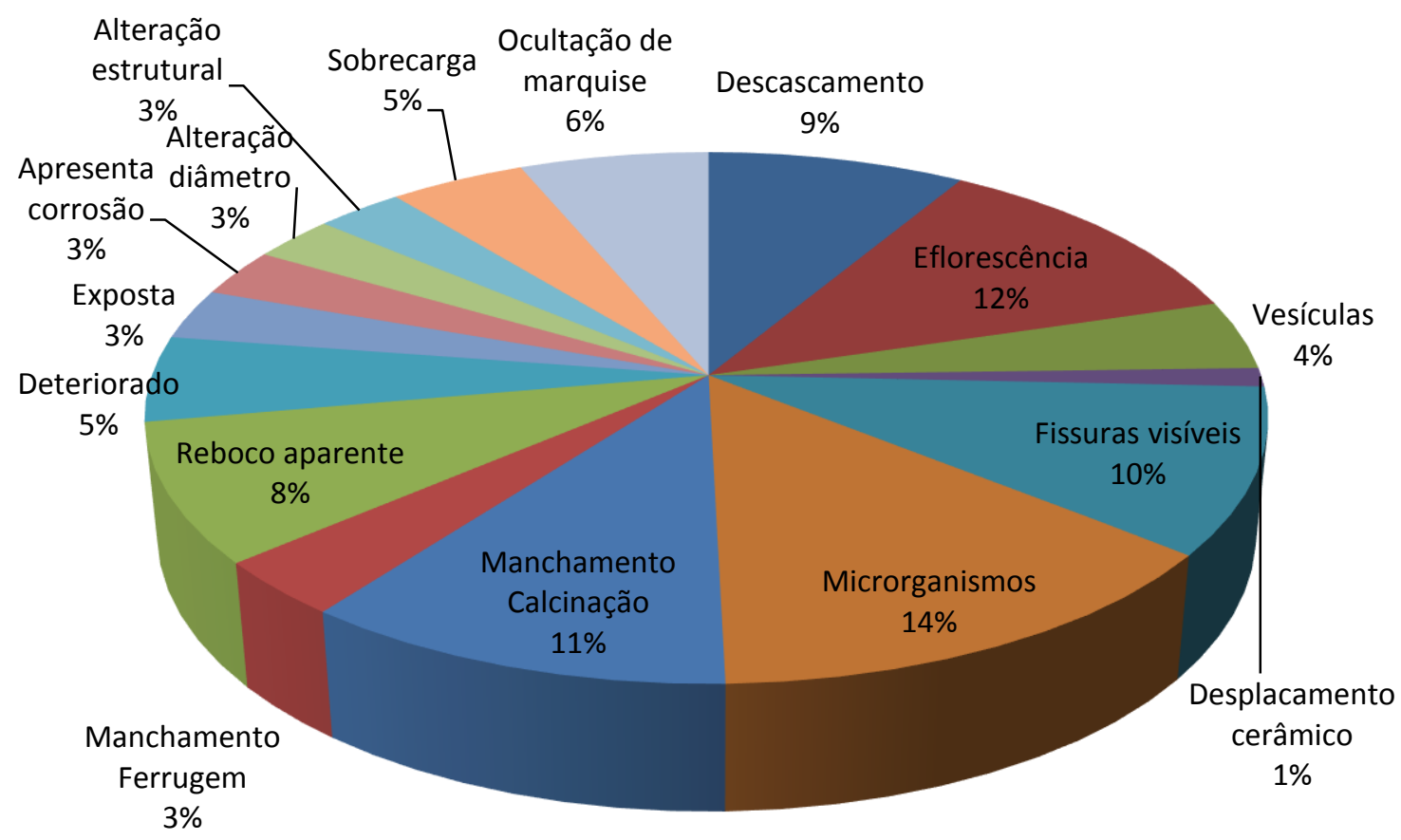

Fonte: Autores (2013)

\section{DISCUSSÃO DOS RESULTADOS}

Como não foram utilizadas técnicas de inferência estatística e consequentemente os dados não foram analisados separada e detalhadamente, por exemplo, não foi estabelecida uma relação de causa e efeito, que poderia ocorrer em marquises com concreto degradado e armadura exposta, pode-se dizer que os resultados demonstram uma caracterização bastante genérica da amostra.

Porém é possível observar que a manifestação mais recorrente é relacionada à presença de microrganismos, tais como fungos e musgos, seguida pelas variáveis relativas à eflorescência. Os dados sugerem uma coerência com o clima local, com altos índices pluviométricos, aliados à falta de manutenção periódica, favorecendo o ambiente quente e úmido no qual tais organismos tendem a se desenvolver. Há de se observar também a amplitude térmica da capital, que pode favorecer a fissuração do concreto, abrindo caminho para entrada de vários agentes agressores.

Outro dado importante é a necessidade de conscientização da população quanto aos problemas decorrentes das patologias em marquises, pois se observa uma postura de mascaramento dos problemas desses elementos estruturais e que em alguns casos observados podem, mesmo sem uma análise mais profunda, ser consideradas em estado crítico de conservação. Afinal o responsável pelo imóvel responde civil e criminalmente por qualquer acidente.

Havendo, finalmente, a contabilização das amostras e suas variáveis nota-se que a frequência das manifestações ultrapassa a metade do total avaliado, o que é um indicativo preocupante para uma cidade que recebe um grande fluxo de pessoas diariamente, como é o caso do centro de Vitória. 


\section{CONCLUSÕES}

Avaliando o estado geral das marquises foi possível constatar que a maior parte da amostra analisada apresenta algum tipo de manifestação patológica, sendo que as mais incidentes foram incidência de micro-organismos, eflorescências, manchamento por calcinação e fissuras visíveis. Esse resultado é resultado coerente uma vez que a região em que essas marquises estão inseridas colabora para essa situação.

Os fatores que influenciaram na deterioração das marquises foram as condições do meio em que elas estão inseridas: elevada umidade relativa do ar, grande concentração de íons cloreto devido à proximidade com a baía de Vitória e presença constante do $\mathrm{CO}_{2}$ devido ao fluxo intenso de veículos. Aliado a essas ocorrências está o fato de se tratar de edificações antigas e que não passam por manutenções periódicas.

Em alguns casos analisados foi possível detectar que havia um risco eminente de desabamento. Apesar de não ter sido a manifestação mais incidente foi uma manifestação preocupante. Há uma necessidade de intervenção urgente nas marquises avaliadas de forma a corrigir os problemas verificados para que possa evitar danos maiores.

\section{REFERÊNCIAS}

ASSOCIAÇÃO BRASILEIRA DE NORMAS TÉCNICAS. NBR 6118 - Projeto de estruturas de concreto - Procedimento. Rio de Janeiro, 2014.

ALBUQUERQUE, Leonel. Foto Aérea de Vitória - ES. Fotografia. Mar.2009. Extraído de <https://www.flickr.com/photos/fotoaereabrasil/3369708444>. Acesso em 20 de abril de 2013.

CARMO, M. Antônio. Estudo da deterioração de marquises de concreto armado nas cidades de Uberlândia e Bambuí. Dissertação de mestrado, UFU-Feciv, Uberlândia. SP. 2009. Disponível em < http://www.ppgec.feciv.ufu.br/node/267 >. Acesso em 18 de abril de 2013.

CASTRO, Eliane K. Desenvolvimento de metodologia para manutenção de estruturas de concreto armado. Dissertação de Mestrado. Universidade de Brasília, Brasília, 185p, dezembro, 1994. Disponível em < http://www.estruturas.unb.br/index.php?option=com_content $\&$ view $=$ article $\& i d=105 \% 3$ Ateses-e-dissertacoes-1994\&catid=51\&Itemid=80\&lang=en $>$. Acesso em $18 \mathrm{de}$ abril de 2013.

RIZZO, Bruno E. MARQUISES - uma abordagem técnica. Centro de estudos e pesquisa de desastres. Subsecretaria de Defesa Civil - Rio de Janeiro. (s.d.). Disponível em <http://www0.rio.rj.gov.br/defesacivil/PDF/marquise_o_que_fazer.pdf $>$. Acesso em 20 de abril de 2013.

SEGAT, G. Tramontina. Manifestações patológicas observadas em revestimentos de argamassa: estudo de caso em Conjunto Habitacional Popular na cidade de Caxias do Sul (RS). Trabalho de conclusão de mestrado profissional, UFRS, 2005. Disponível em < http://www.lume.ufrgs.br/handle/10183/10139 >. Acesso em 20 de abril de 2013.

VITÓRIA, Prefeitura Municipal. Secretaria de desenvolvimento da cidade. Vitória em dados: História dos bairros - Centro. (s.d) Disponível em <http://legado.vitoria.es.gov.br/regionais/bairros/regiao1/centro.asp>. Acesso em $18 \mathrm{de}$ abril de 2013. 